\title{
New application of an old drug: Antitumor activity and mechanisms of doxycycline in small cell lung cancer
}

\author{
SHENG-QI WANG $^{1 *}$, BO-XIN ZHAO ${ }^{1 *}$, YUAN LIU ${ }^{1}$, YA-TIAN WANG ${ }^{1}$, QIAN-YING LIANG ${ }^{1}$, \\ YUN CAI $^{1}$, YUN-QI ZHANG ${ }^{1}$, JIANG-HONG YANG ${ }^{2}$, ZHI-HUA SONG $^{1}$ and GUO-FENG LI ${ }^{1}$ \\ ${ }^{1}$ Department of Pharmacy, Nanfang Hospital, Southern Medical University, Guangzhou, Guangdong 510515; \\ ${ }^{2}$ Department of Pharmaceutics, School of Pharmacy, Ningxia Medical University, Yinchuan, Gansu 750004, P.R. China
}

Received December 7, 2015; Accepted January 11, 2016

DOI: 10.3892/ijo.2016.3375

\begin{abstract}
Small cell lung cancer (SCLC) remains one of the most aggressive tumors with a poor prognosis. The clinical outcome of SCLC patients has reached its plateau with the existing standard treatment and thus new therapies are urgently required. Accumulating evidences have indicated that doxycycline, a commonly used antibiotic, has antitumor activity against several malignancies. However, whether doxycycline has antitumor activity in SCLC and its underlying mechanisms remain unclear. Our investigation demonstrated that doxycycline could significantly inhibit the proliferation and colony formulation of SCLC cells $(\mathrm{p}<0.05)$. Furthermore, both Hoechst 33258 dye staining and TUNEL assays indicated that doxycycline could induce remarkable apoptosis of H446 cells in a concentration-dependent manner. RT-PCR and western blot assays proved that apoptosis induction effect of doxycycline was achieved via inducing the expression of caspase-3 and bax, as well as attenuating the expression of survivin and bcl-2. Moreover, the wound healing assay and Transwell assay indicated that doxycycline could significantly suppress the migration and invasion of H446 cells in a concentration-dependent manner $(\mathrm{p}<0.05)$. ELISA assay proved that the inhibitory effect of doxycycline on the migration and invasion of $\mathrm{H} 446$ cells was achieved via decreasing the secretion of MMP-2, MMP-9 and VEGF, as well as increasing the secretion of TIMP-2. Taken together, doxycycline dose-dependently suppressed the proliferation,
\end{abstract}

Correspondence to: Professor Guo-Feng Li or Dr Zhi-hua Song, Department of Pharmacy, Nanfang Hospital, Southern Medical University, No. 1838 Guangzhou North Road, Guangzhou, Baiyun, Guangdong 510515, P.R. China

E-mail: liguofeng_2010@126.com

E-mail: ahua19821013@163.com

${ }^{*}$ Contributed equally

Key words: doxycycline, small cell lung cancer, proliferation, apoptosis, migration, invasion colony formulation, migration and invasion of SCLC cells, as well as induced apoptosis. These findings encourage further investigations on the potential of doxycycline as a candidate drug for the treatment of SCLC.

\section{Introduction}

Lung cancer remains the most common cause of cancer-related death worldwide, and was responsible for 1.56 million deaths annually, as of 2012 (1). The main primary types are small cell lung cancer (SCLC) and non-small cell lung cancer (NSCLC). Compared with NSCLC, SCLC has a more aggressive behavior due to its higher proliferative index and tends to spread in its early stages. Combination chemotherapy, generally platinumbased plus etoposide or irinotecan, is the mainstay first-line treatment for metastatic SCLC patients $(2,3)$. Despite the initial sensitivity, the long-term outcomes of the majority of SCLC patients remain poor due to early relapse and acquired resistance (2). In addition, the vast majority of patients with SCLC fail to respond to tyrosine-kinase inhibitors against the epidermal growth factor receptor (EGFR) (4). Except for topotecan, few treatment options then remain $(2,5,6)$. Therefore, it is urgent to develop novel and more effective therapeutic drugs for the treatment of SCLC patients.

Doxycycline (DOXY) is a member of the tetracycline family of antibiotics in widespread clinical use. Accumulating evidence has suggested that doxycycline has antitumor activity against several kinds of malignancies. It has been reported that doxycycline has anti-metastatic activity and cytotoxicity in melanoma and breast carcinoma $(7,8)$. Doxycycline was able to mediate mesenchymal to epithelial transition in ovarian cancer cells (9). Doxycycline could induce apoptosis in pancreatic cancer cells (10). Doxycycline treatment could result in a reduction in total tumor burden in a bone metastasis mouse model of human breast cancer (11). All these studies demonstrate that this well-tolerated antibiotic may also be effective in treatment of other human cancers and is a candidate antitumor drug of great research value.

Therefore, in this study, to investigate whether doxycycline has therapeutic potential in small cell lung cancer, we investigated the effects of doxycycline on the proliferation, colony formulation, apoptosis, migration and invasion of human small cell lung cancer cell lines and identified its mechanisms. 


\section{Materials and methods}

Reagents and antibodies. Doxycycline and Hoechst 33258 was purchased from Sigma Chemical Co. (St. Louis, MQ, USA). 5-fluorouracil was obtained from Xudong Haipu Pharmaceutical Co.,Ltd. (Shanghai, China). Primary antibodies against survivin, bax, bcl-2 and caspase-3 were purchased from Cell Signaling Technology, Inc. (Danvers, MA, USA). Antibody against $\beta$-actin was obtained from Beyotime Biotechnology, Inc. (Shanghai, China). The HRP-conjugated goat anti-rabbit secondary antibody and goat anti-mouse secondary antibody were purchased from Cell Signaling Technology, Inc.

Cell culture. The SCLC H446 and H1688 cells were obtained from the Cancer Center of Nanfang Hospital in Southern Medical University. Cells were routinely cultured in RPMI-1640 (Gibco, Grand Island, NY, USA), supplemented with $10 \%$ fetal bovine serum (FBS; Sijiqing, Hangzhou, China) and $1 \%$ penicillin $(10000 \mathrm{U} / \mathrm{ml}) /$ streptomycin $(10 \mathrm{mg} / \mathrm{ml})$ solution (Bosheng, Shanghai, China). The cultures were incubated in a humidified incubator at $37^{\circ} \mathrm{C}$ and $5 \% \mathrm{CO}_{2}$ atmosphere.

Cytotoxicity assay. The sensitivity of SCLC H446 and H1688 cells to doxycycline treatment was measured by using the Cell Counting Kit-8 (Beyotime, Shanghai, China) according to the manufacturer's instructions (12). The $\mathrm{IC}_{50}$ was calculated from survival curves using the Bliss method (13).

Colony formation assay. For colony formation assays, $3 \times 10^{2} \mathrm{H} 446$ cells were plated in triplicate into 12 -well plates in RPMI-1640 medium supplemented with different concentrations of doxycycline or 5-fluorouracil for $48 \mathrm{~h}$. Subsequently, the medium supplemented with drugs was changed to complete medium. After a seven-day routine culture, the colonies were fixed and then visualized by staining with $0.04 \%$ crystal violet for $30 \mathrm{~min}$. A colony with more than 50 cells was counted under a light microscope (x200). The colony formation rate was calculated using the following formula:

$$
\text { Colony formation rate }(\%) \frac{\text { Number of colonies }}{\text { Number of cells seeded }} \times 100 \%
$$

Morphological observation of apoptosis. Hoechst 33258 dye staining was carried out to observe the morphological changes of cell apoptosis induced by doxycycline (14). Briefly, H446 cells were seeded at a density of $1 \times 10^{5}$ cells per well in 24-well plates and treated with different concentrations of doxycycline or 5-fluorouracil for $48 \mathrm{~h}$. Subsequently, cells were collected by trypsinization and centrifugation at $1000 \mathrm{rpm}$ for $3 \mathrm{~min}$. After washing twice in PBS, the resultant cells were fixed in 4\% paraformaldehyde for $30 \mathrm{~min}$. Then, after washing three times in PBS, the fixed cells were incubated with $5 \mathrm{mg} / \mathrm{l}$ Hoechst 33258 for $30 \mathrm{~min}$. Cells were then added to slides and observed under a fluorescence microscope. The excitation wavelength and emission wavelength were set at 350 and $460 \mathrm{~nm}$, respectively.

TUNEL assay. TUNEL assay was performed using the TUNEL Apoptosis Assay kit (KeyGen, Nanjing, China) following the manufacturer's instructions (15). Then, the apoptotic cells (stained in brown or dark brown) were observed under a light microscope. Ten microscopic vision fields (x200) were selected and 100 cells in each vision field were counted. The apoptosis index (AI) was calculated using the following formula:

$$
\mathrm{AI}=\frac{\text { The sum of apoptosis cells }}{\text { The sum of cells counted }} \times 100 \%
$$

Wound healing assay. The wound healing assay was performed to investigate the effect of doxycycline on the migration of $\mathrm{H} 446$ cells. Briefly, H446 cells at $90 \%$ confluency were wounded with a $10 \mu \mathrm{l}$ sterile pipette tip, washed with PBS, and replenished with serum-free RPMI-1640 medium supplemented with different concentrations of doxycycline or 5-fluorouracil. Images were captured using an inverted microscope at $48 \mathrm{~h}$ after wounding. The Image-pro Plus software was used to measure the migration distance.

Transwell assay. Invasion assay was performed in Transwell inserts with $8-\mu \mathrm{m}$ pore (Corning, NY, USA). Serum-starved H446 cells were trypsynized and counted. Cells $\left(5 \times 10^{5}\right)$ in $200 \mu$ l serum-free medium were placed into the upper chamber. The lower chamber was filled with $400 \mu 1$ RPMI-1640 medium containing $10 \%$ FBS. After $24 \mathrm{~h}$ culture, cells that migrated to the lower chamber were fixed in $4 \%$ paraformaldehyde, stained with crystal violet staining solution and counted under a light microscope. Invasion inhibition rate (IR) was calculated using the following formula:

$$
\text { IR }=1-\frac{\text { Migrated cells of the experimental group }}{\text { Migrated cells of the control group }} \times 100 \%
$$

RNA extraction, $c D N A$ synthesis and RT-PCR. Total RNA was extracted with TRIzol and reverse-transcribed to complementary cDNA using the PrimeScript ${ }^{\mathrm{TM}}$ RT reagent kit (Takara, Shiga, Japan) according to the manufacturer's instructions. RT-PCR was performed using the SYBR Premix Ex Taq kit (Takara) and the MX3005P Quantitative PCR Systems (Applied Biosystems, Foster City, CA, USA). The sequences of specific PCR primers were 5'-CTTTGCCA GCAAACTGG TGC-3' (forward) and 5'-GAGTCTCACCC AACCACCCT-3' (reverse) for bax; 5'-CCCTGTGGATGA CTGAGTACC-3' (forward) and 5'-GCCGTACAGTTCC ACAAAGG-3' (reverse) for bcl-2; 5'-GTGAGGCGGTTG TAGAAGAGTT-3' (forward) and 5'-TCACGGCCTGGGA TTTCAAG-3' (reverse) for caspase-3; 5'-TTCTGCTTCAA GGAGCTGG-3' (forward) and 5'-GCACTTTCTCCGCA GTTTC-3' (reverse) for survivin; 5'-TGTTACAGGAAGTC CCTTGCCATC-3' (forward) and 5'-CTGTGTGGACTTG GGAGAGGAC-3' (reverse) for $\beta$-actin.

Western blotting. Protein extracts were obtained by lysing cells with RIPA (Beyotime). Protein concentrations were quantified using the BCA Protein Assay kit (Beyotime). Equal amounts of protein $(20 \mu \mathrm{g})$ were resolved by SDS-PAGE on a $10 \%$ polyacrylamide gel and transferred onto a polyvinylidene fluoride membrane. After saturation in $7.5 \%$ nonfat milk at room temperature for $1 \mathrm{~h}$, the membranes were incubated overnight in the corresponding primary antibodies at $4^{\circ} \mathrm{C}$. Then, bound antibodies onto membranes were detected using horseradish 

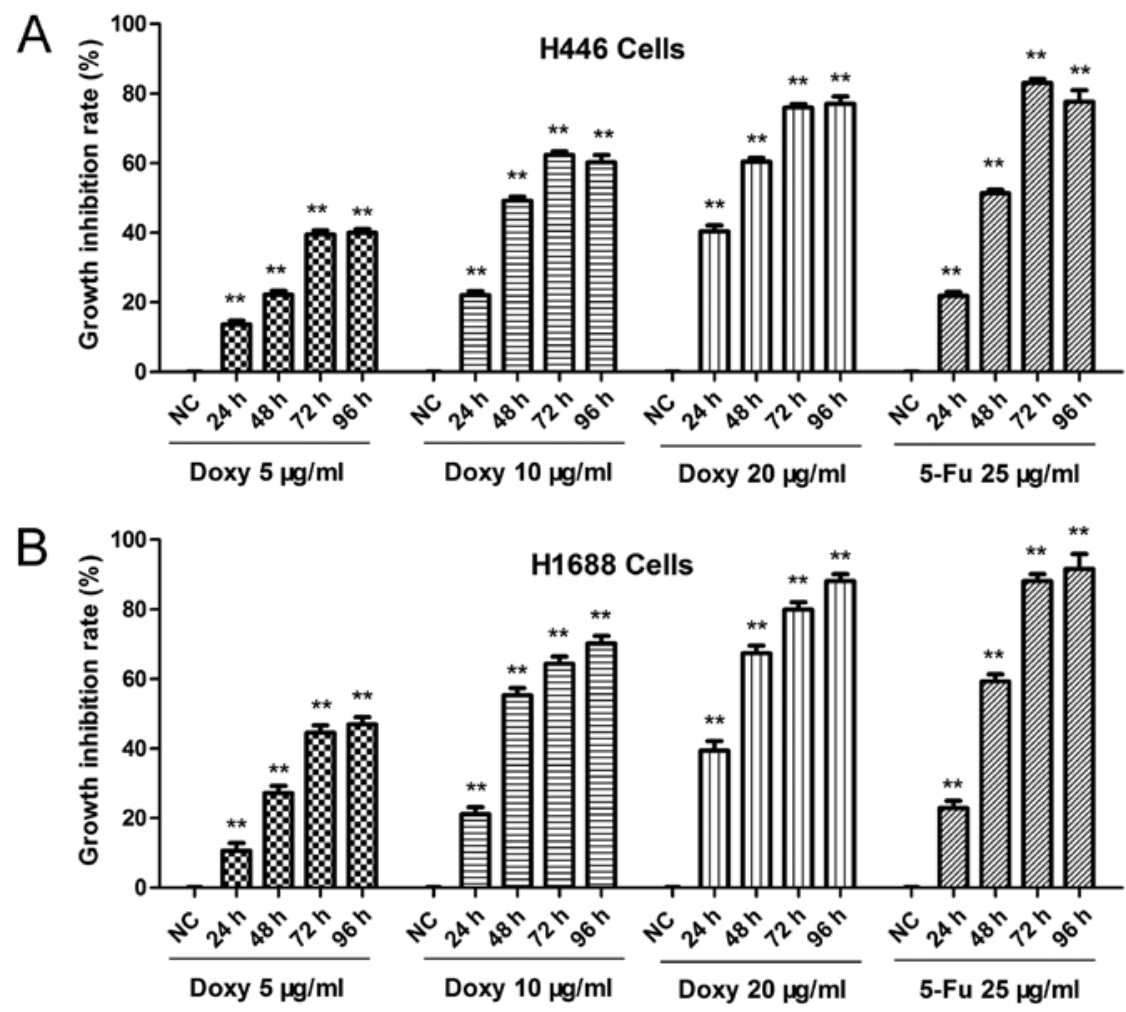

Figure 1. Doxycycline inhibits the proliferation of H446 and H1688 cells in a concentration- and time-dependent manner." $\mathrm{p}<0.05$

peroxidase-conjugated secondary antibodies, followed by the enhanced chemiluminescence detection reagents (Millipore, Billerica, MA, USA).

ELISA assay. Effects of doxycycline on the secretion of MMP-2, MMP-9, VEGF and TIMP-2 into the supernatant from $\mathrm{H} 446$ cells were investigated by ELISA assay using corresponding ELISA kit (Cusabio Biotech, Wuhan, China) according to the manufacturer's instructions.

Statistical analysis. The data are expressed as the mean \pm standard deviation. Statistical analyses between groups were calculated by One-way ANOVA. $\mathrm{p}<0.05$ was considered to indicate a statistically significant difference.

\section{Results}

Doxycycline inhibits the proliferation of $H 446$ and H1688 cells in a concentration- and time-dependent manner. CCK-8 assay was performed to investigate the cytotoxic effect of doxycycline on SCLC cells. As shown in Fig. 1, both H446 cells and H1688 cells were sensitive to doxycycline treatment. Doxycycline inhibited the proliferation of H446 and H1688 cells in a concentration- and time-dependent manner. For example, the $\mathrm{IC}_{50}$ values of doxycycline on $\mathrm{H} 446$ cells were $24.10 \mu \mathrm{g} / \mathrm{ml}$ for the $24 \mathrm{~h}$ treatment group, $10.98 \mu \mathrm{g} / \mathrm{ml}$ for the $48 \mathrm{~h}$ treatment group, $8.20 \mu \mathrm{g} / \mathrm{ml}$ for the $72 \mathrm{~h}$ treatment group and $8.03 \mu \mathrm{g} / \mathrm{ml}$ for the $96 \mathrm{~h}$ treatment group. In addition, 5-fluorouracil was used as a positive control cytotoxic drug in this study. As shown in Fig. 1, doxycycline had a similar or even stronger inhibitory effect on the proliferation of H446 and H1688 cells than 5-fluorouracil. These results indicated
A

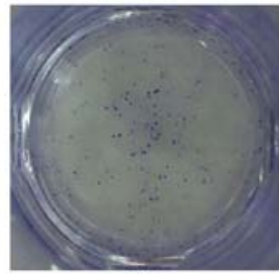

$\mathrm{NC}$
Doxy $5 \mu \mathrm{g} / \mathrm{ml}$

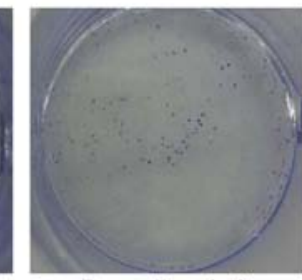

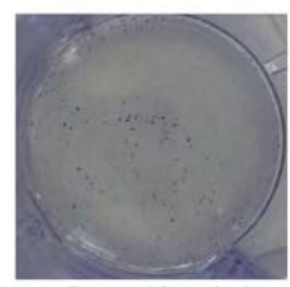

Doxy $10 \mu \mathrm{g} / \mathrm{ml}$

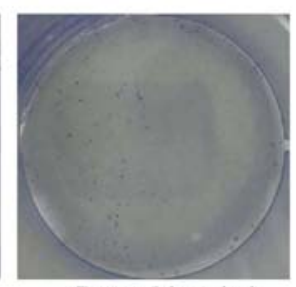

Doxy $20 \mu \mathrm{g} / \mathrm{ml}$

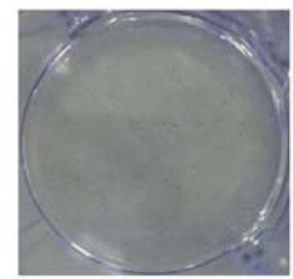

$5-\mathrm{FU} 25 \mu \mathrm{g} / \mathrm{ml}$
B

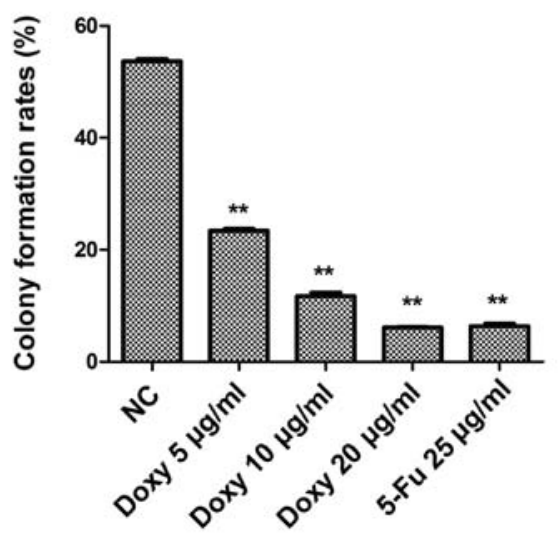

Figure 2. Doxycycline suppresses the colony formulation of H446 cells (A) Images of colony formulation assay for each group; (B) the colony formation rates for each group. ${ }^{* *} \mathrm{p}<0.05$ vs. control group. 


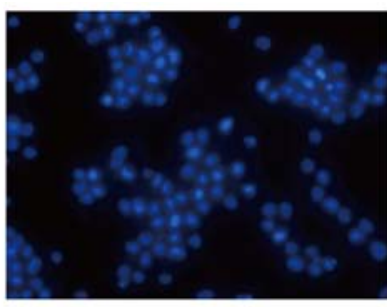

NC

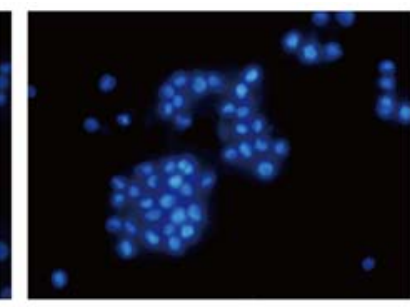

Doxy $5 \mu \mathrm{g} / \mathrm{ml}$

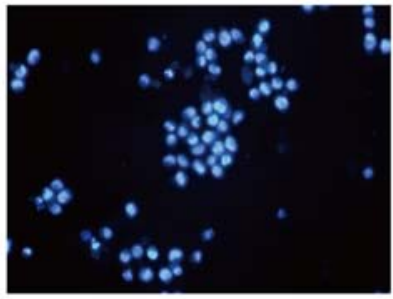

Doxy $10 \mu \mathrm{g} / \mathrm{ml}$

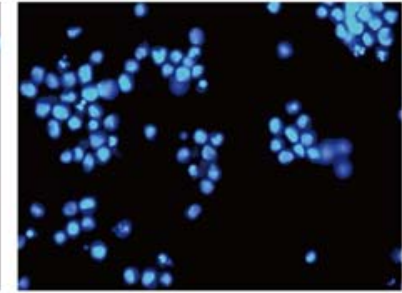

Doxy $20 \mu \mathrm{g} / \mathrm{ml}$

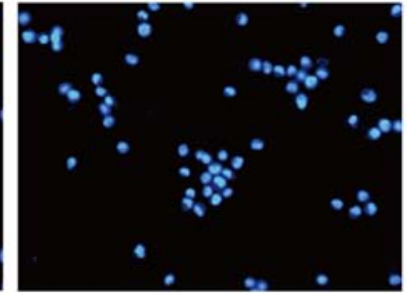

$5-\mathrm{FU} 25 \mu \mathrm{g} / \mathrm{ml}$

Figure 3. Hoechst 33258 dye staining assay confirmation that doxycycline induces apoptosis of H446 cells.

that doxycycline was a potential cytotoxic candidate drug in the treatment of SCLC.

Doxycycline suppresses the colony formulation of $\mathrm{H} 446$ cells. As shown in Fig. 2, the colony formation rates (\%) were $53.68 \pm 0.45$ for the control group, $23.43 \pm 0.33$ for the $5 \mu \mathrm{g} / \mathrm{ml}$ doxycycline group, $11.74 \pm 0.64$ for the $10 \mu \mathrm{g} / \mathrm{ml}$ doxycycline group, $6.14 \pm 0.06$ for the $20 \mu \mathrm{g} / \mathrm{ml}$ doxycycline group and $6.33 \pm 0.48$ for the $25 \mu \mathrm{g} / \mathrm{ml} 5$-fluorouracil group. Doxycycline markedly suppressed the colony formulation of H446 cells in a concentration-dependent manner $(\mathrm{p}<0.05)$.

Doxycycline induces apoptosis of $H 446$ cells via regulating the expression of caspase-3, survivin, bax and bcl-2. Inducing apoptosis might partly be the reason that led to the inhibitory effect of doxycycline on proliferation and colony formation of H446 cells. As shown in Fig. 3, untreated H446 cells were only lightly stained with Hoechst 33258 dye and exhibited a misty light blue appearance under the fluorescent microscope. However, doxycycline treated H446 cells were deeply stained with Hoechst 33258 and exhibited a bright blue appearance. In addition, doxycycline treated $\mathrm{H} 446$ cells exhibited signs of shrunken cell bodies, nuclear fragmentation and the formation of apoptotic bodies.

TUNEL assay. Fig. 4A and B show apoptotic $\mathrm{H} 446$ cells with brown-stained nuclei, and the apoptotic indexes $(\%)$ were $1.78 \pm 0.29$ for the control group, $33.17 \pm 0.45$ for the $5 \mu \mathrm{g} / \mathrm{ml}$ doxycycline group, $51.14 \pm 0.96$ for the $10 \mu \mathrm{g} / \mathrm{ml}$ doxycycline group, $64.25 \pm 1.08$ for the $20 \mu \mathrm{g} / \mathrm{ml}$ doxycycline group and $68.72 \pm 2.12$ for the $25 \mu \mathrm{g} / \mathrm{ml} 5$-fluorouracil group. TUNEL staining also showed that there were significantly increased proportions of apoptotic H446 cells in the doxycycline groups when compared with those in the control group.

To investigate the mechanisms by which doxycycline induced the apoptosis of H446 cells, RT-PCR and western blot assays were carried out to determine the expression changes of apoptosis-related proteins. As demonstrated in Fig. 4C and D, doxycycline strongly induced the expression of caspase- 3 in $\mathrm{H} 446$ cells both in the mRNA and protein level in a concentration-dependent manner, whereas it decreased the expression of survivin. In addition, doxycycline treatment also increased the ratio of Bax/Bcl-2 in $\mathrm{H} 446$ cells. These results may raise the possibility that doxycycline enables $\mathrm{H} 446$ cells to become highly susceptible to apoptosis via activation of pro-apoptosis genes (caspase-3 and bax) and suppression of anti-apoptosis genes (survivin and bcl-2).

Doxycycline suppresses the migration efficacy of H446 cells. The wound-healing assay was carried out to investigate the effect of doxycycline on the migration efficacy of H446 cells. Confluent cells were scraped with a sterile pipette tip, and the remaining cells were allowed to migrate into the gap. As shown in Fig. 5A and $\mathrm{C}$, the migration distances were $0.56 \pm 0.02 \mathrm{~mm}$ for the control group, $0.43 \pm 0.01 \mathrm{~mm}$ for the $5 \mu \mathrm{g} / \mathrm{ml}$ doxycycline group, $0.32 \pm 0.01 \mathrm{~mm}$ for the $10 \mu \mathrm{g} / \mathrm{ml}$ doxycycline group, $0.11 \pm 0.01 \mathrm{~mm}$ for the $20 \mu \mathrm{g} / \mathrm{ml}$ doxycycline group and $0.11 \pm 0.01 \mathrm{~mm}$ for the $25 \mu \mathrm{g} / \mathrm{ml} 5$-fluorouracil group. The wound gap of H446 cells was significantly wider in the doxycycline-treated groups than that in the untreated groups $(\mathrm{p}<0.05)$. Doxycycline significantly suppressed the migration efficacy of $\mathrm{H} 446$ cells in a concentration-dependent manner $(\mathrm{p}<0.05)$.

Doxycycline suppresses the invasion efficacy of H446 cells. Transwell assay was performed to investigate the effect of doxycycline on the invasion efficacy of H446 cells. As shown in Fig. 5B and D, the invasion inhibition rates were $43.71 \%$ for the $5 \mu \mathrm{g} / \mathrm{ml}$ doxycycline group, $58.70 \%$ for the $10 \mu \mathrm{g} / \mathrm{ml}$ doxycycline group, $81.33 \%$ for the $20 \mu \mathrm{g} / \mathrm{ml}$ doxycycline group and $82.25 \%$ for the $25 \mu \mathrm{g} / \mathrm{ml} 5$-fluorouracil group. Doxycycline significantly suppressed the invasion efficacy of H446 cells in a concentration-dependent manner $(\mathrm{p}<0.05)$.

Doxycycline suppresses the migration and invasion of $H 446$ cells via regulating the secretion of MMP-2, MMP-9, TIMP-2 
A

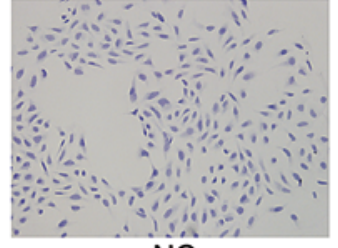

NC

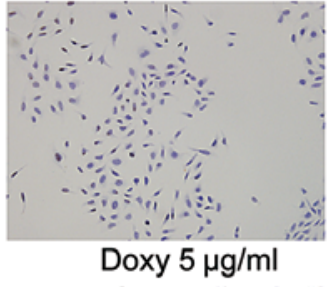

Doxy $5 \mu \mathrm{g} / \mathrm{ml}$

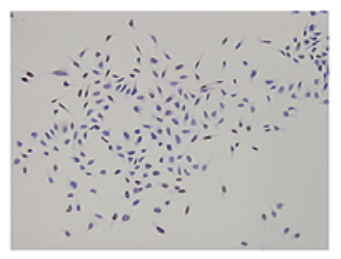

Doxy $10 \mu \mathrm{g} / \mathrm{ml}$

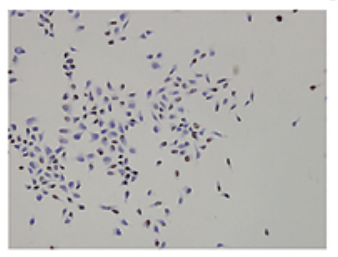

Doxy $20 \mu \mathrm{g} / \mathrm{ml}$

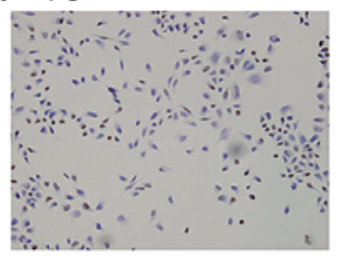

$5-\mathrm{FU} 25 \mu \mathrm{g} / \mathrm{ml}$
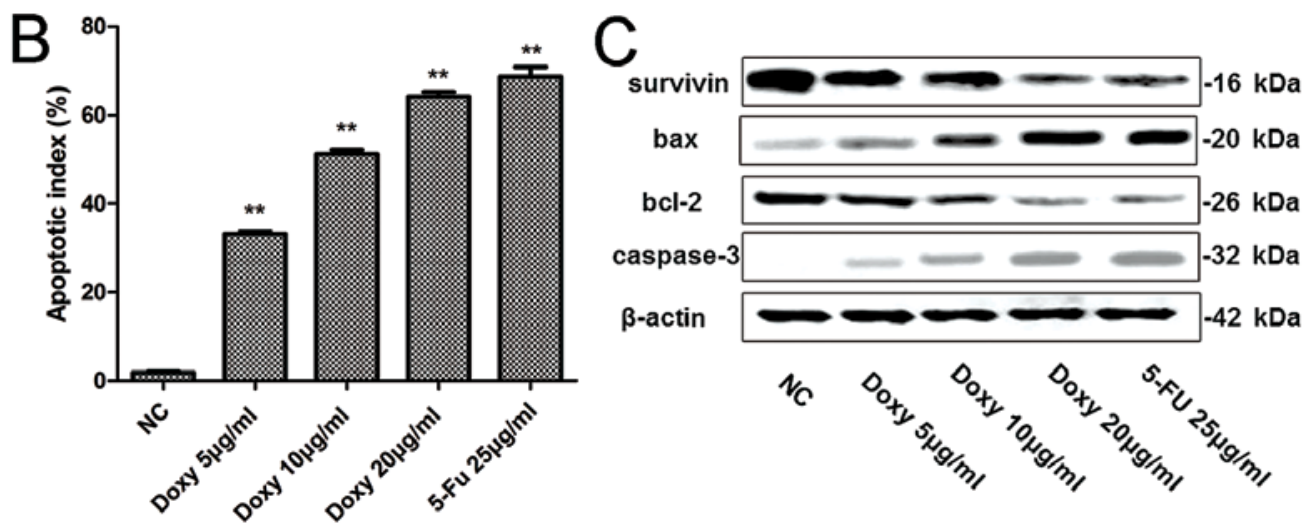

D

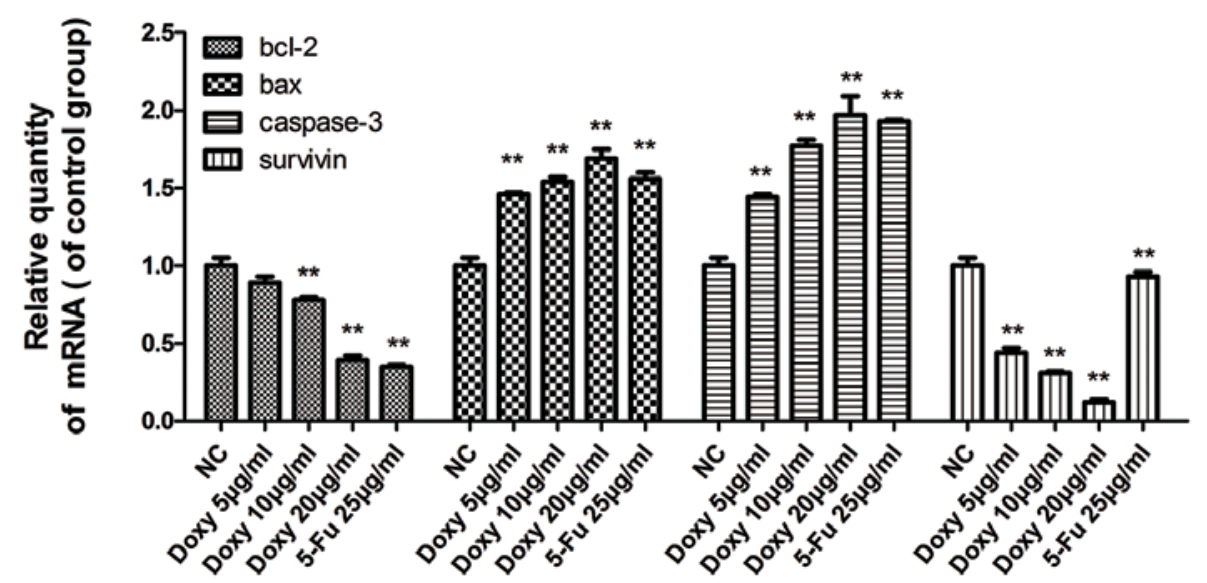

Figure 4. Doxycycline induces apoptosis of H446 cells via regulating the expression of survivin, bax, bcl-2 and caspase-3. (A) Effects of doxycycline on apoptosis of $\mathrm{H} 446$ cells were investigated by TUNEL assay; (B) the apoptotic indexes for each group, ${ }^{* *} \mathrm{p}<0.05$ vs. control group. (C) Effects of doxycycline on the protein expression of bcl-2, bax, caspase-3 and survivin were investigated by western blot assay; (D) Effects of doxycycline on the mRNA expression of survivin, bax, bcl-2 and caspase- 3 were investigated by RT-PCR assay.

and VEGF. ELISA assays were performed to investigate the mechanisms by which doxycycline suppressed the migration and invasion of $\mathrm{H} 446$ cells. Increased matrix metalloproteinase (MMP) and VEGF activity of tumor cells correlates with a higher invasive and metastatic potential (11). Thus, blocking the synthesis or release of MMPs or VEGF may result in shrinkage of invasive efficacies of the SCLC cells. As shown in Table I, doxycycline significantly decreased the secretion of MMP-2, MMP-9 and VEGF from H446 cells, whereas it increased the secretion of TIMP-2 (a selective inhibitor of MMPs) $(\mathrm{p}<0.05)$.

\section{Discussion}

SCLC remains one of the most aggressive tumors with a poor prognosis. Combination chemotherapy, generally platinumbased plus etoposide or irinotecan, is the mainstay first-line treatment for metastatic SCLC patients (2). However, the majority of SCLC patients are diagnosed at an advanced stage. The patients with advanced SCLC are initially highly sensitive to chemo-treatment, with very high response rates, but invariably relapse. Except for topotecan, few treatment options then remain (2). In addition, the major advances in the treatment 
A
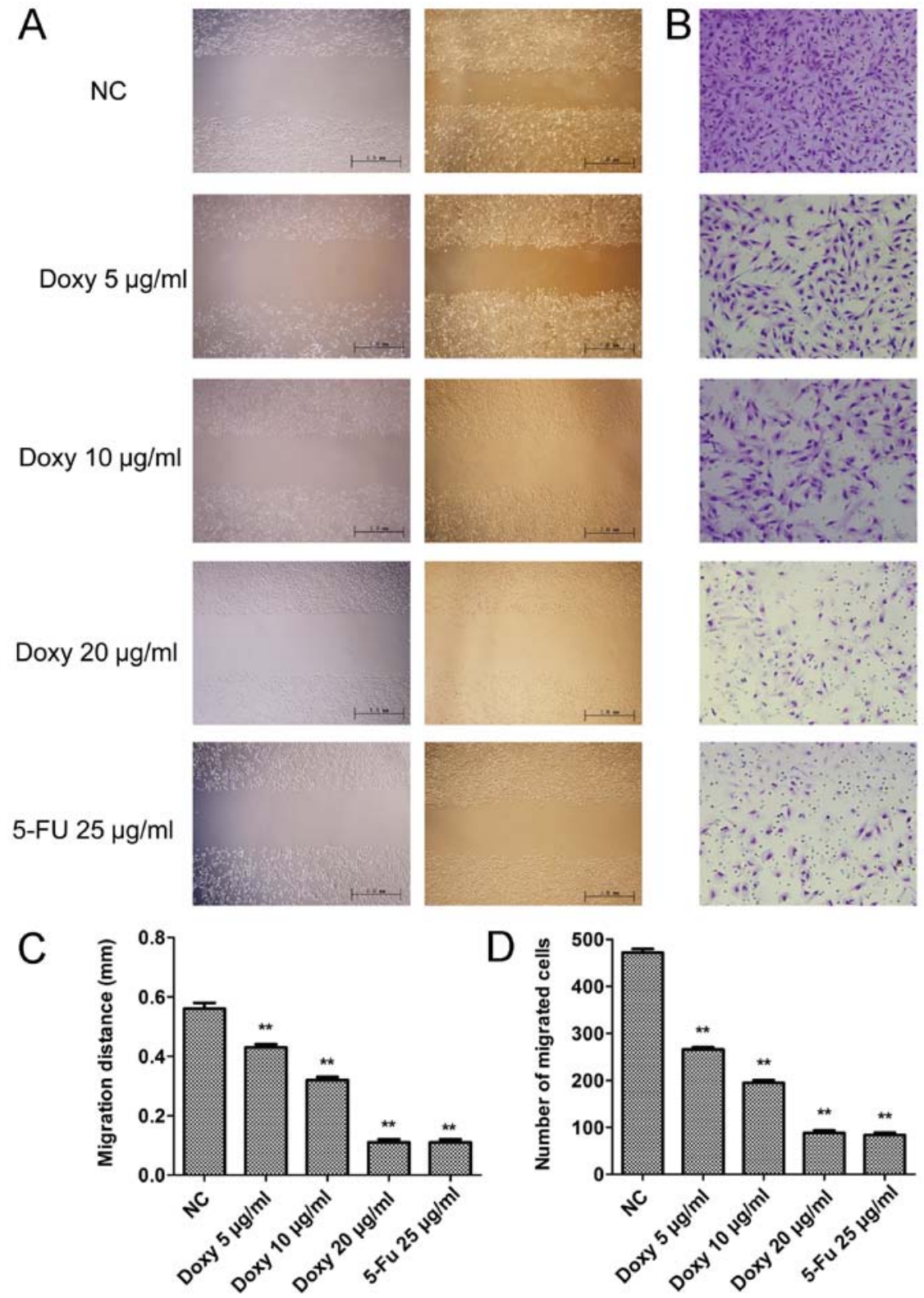

Figure 5. Doxycycline (doxy) suppressed the migration and invasion efficacy of H446 cells. (A) The wound-healing assay was performed to investigate the effect of doxycycline on the migration efficacy of H446 cells. (B) Transwell assay was performed to investigate the effect of doxycycline on the invasion efficacy of H446 cells. (C) The migration distances for each group; (D) the numbers of migrated cells for each group; ${ }^{* *}$ p $<0.05$ vs. control group.

of SCLC have brought only minor improvements in survival in the past decade. Therefore, treatment options are still limited and the prognosis of these patients is still poor (16). It is imperative to develop novel and more effective therapeutic drugs for the treatment of SCLC patients (17).

Re-discovering new applications of existing drugs with known pharmacokinetics and safety profiles is one more efficient solution for the development of new anticancer drugs and is a new trend of pharmaceutical research. There are thousands of proteins and biomolecules in the human body, and the targeting of a certain existing drug is not exclusive. Many studies have reported the new applications of old drugs with ideal treatment outcomes and fewer side effects in recent years. For example, clinical trials have shown that patients with prostate, lung, and basal cell carcinoma have benefited from treatment with itraconazole (a common triazole anti- fungal drug in widespread clinical use), and there are also additional reports of activity in leukaemia, ovarian, breast, and pancreatic cancers (18). In addition, Sarkar et al reported that dopamine may be safely used as an anti-angiogenic drug for the treatment of malignant tumors (19).

Doxycycline has recently been shown to possess non-antibiotic properties including antitumor activity against several tumor types including melanoma (6), ovarian cancer (9), pancreatic cancer $(10)$ and breast cancer $(8,11)$. However, it was unclear whether doxycycline has therapeutic potential in the treatment of SCLC and how doxycycline affects the tumorigenesis pathway of SCLC cells. In the present study, we investigated whether doxycycline treatment could inhibit the proliferation of SCLC H446 and H1688 cells, as uncontrolled proliferation is the most typical biological characteristic of cancer cells. As shown in Fig. 1, doxycycline at concentrations 
Table I. The content of MMP-2, MMP-9, TIMP-2 and VEGF of each group (mean \pm SD, $n=3$ ).

\begin{tabular}{lcccc}
\hline Groups & $\begin{array}{c}\text { MMP-2 } \\
(\mathrm{ng} / \mathrm{ml})\end{array}$ & $\begin{array}{c}\text { MMP-9 } \\
(\mathrm{ng} / \mathrm{ml})\end{array}$ & $\begin{array}{c}\text { TIMP-2 } \\
(\mathrm{ng} / \mathrm{ml})\end{array}$ & $\begin{array}{c}\text { VEGF } \\
(\mathrm{pg} / \mathrm{ml})\end{array}$ \\
\hline $\mathrm{NC}$ & $24.75 \pm 0.53$ & $3.77 \pm 0.05$ & $0.53 \pm 0.05$ & $323.48 \pm 13.32$ \\
Doxy $5 \mu \mathrm{g} / \mathrm{ml}$ & $19.19 \pm 0.23^{\mathrm{c}}$ & $2.81 \pm 0.16^{\mathrm{a}}$ & $0.69 \pm 0.06^{\mathrm{b}}$ & $286.88 \pm 3.14^{\mathrm{c}}$ \\
Doxy $10 \mu \mathrm{g} / \mathrm{ml}$ & $16.41 \pm 0.14^{\mathrm{c}}$ & $2.05 \pm 0.14^{\mathrm{b}}$ & $0.99 \pm 0.07^{\mathrm{c}}$ & $260.37 \pm 3.66^{\mathrm{c}}$ \\
Doxy $20 \mu \mathrm{g} / \mathrm{ml}$ & $14.71 \pm 0.32^{\mathrm{c}}$ & $1.64 \pm 0.04^{\mathrm{c}}$ & $1.37 \pm 0.02^{\mathrm{c}}$ & $230.93 \pm 5.30^{\mathrm{c}}$ \\
$5-\mathrm{Fu} 25 \mu \mathrm{g} / \mathrm{ml}$ & $15.35 \pm 0.51^{\mathrm{c}}$ & $1.42 \pm 0.05^{\mathrm{c}}$ & $1.21 \pm 0.07^{\mathrm{c}}$ & $218.77 \pm 10.30^{\mathrm{c}}$ \\
\hline
\end{tabular}

${ }^{\mathrm{a}} \mathrm{p}<0.05,{ }^{\mathrm{b}} \mathrm{p}<0.01,{ }^{\mathrm{c}} \mathrm{p}<0.001$ vs. control group.

from 5 to $20 \mu \mathrm{g} / \mathrm{ml}$ could significantly inhibit the proliferation of SCLC H446 and H1688 cells, which was even more cytotoxic than $20 \mu \mathrm{g} / \mathrm{ml} 5$-fluorouracil (a common chemotherapy drug) under some circumstances. The action concentration ( 5 to $20 \mu \mathrm{g} / \mathrm{ml}$ ) was also close to the human blood concentration of doxycycline during antibacterial treatment in the clinic, which further improved the possibility of the doxycycline new application for SCLC treatment. In addition, colony forming rates of drug-treated cancer cells can reflect the self-healing ability of cancer cells. Cancer cells with higher self-healing abilities are more likely to relapse after chemotherapy treatment. As shown in Fig. 2, doxycycline remarkably suppressed the colony formulation of $\mathrm{H} 448$ cells. Taken together, these results indicated that doxycycline inhibited the proliferation and colony formation of SCLC cells.

Inducing apoptosis might be one of the mechanisms by which doxycycline inhibited the growth of SCLC cells. As shown in Figs. 3 and 4A, both Hoechst 33258 dye staining and TUNEL assay proved that doxycycline could significantly induce apoptosis of $\mathrm{H} 446$ cells. In the process of cell apoptotic death, the two central pathways are the mitochondrial pathway and the caspase protease pathway (20). In viable cells, doxycycline is transferred into the cytoplasm and localizes in mitochondria, where it is metabolized to stable photoproducts, such as lumidoxycycline, which induces mitochondrial fragmentation and alters mitochondrial membrane integrity, leading to continuous inhibition of mitochondrial protein synthesis (21). Therefore, we firstly assessed the effect of doxycycline on the mitochondrial pathway during the apoptosis induction process. Pro-apoptosis protein bax and anti-apoptosis protein bcl-2 are the main modulators of the mitochondrial pathway. It has also been reported that expression of bcl-2 protein was prevalent in nearly $90 \%$ SCLC patients (22). Herein, doxycycline treatment increased the ratio of bax/bcl-2 both in the mRNA and protein level in H446 cells (Fig. 4C and D), suggesting its potential in inducing apoptosis. In addition, caspase- 3 is the most important modulator of the caspase protease-mediated apoptosis pathway in mammals. It is regarded as the 'activator' and 'performer' of the caspase protease-mediated apoptosis cascade reaction (21). Survivin is a new member of the anti-apoptosis protein family and is overexpressed in multiple cancer cell lines $(23,24)$. Doxycycline treatment induced the expression of caspase- 3 both in the mRNA and protein levels, whereas it attenuated the expression of survivin (Fig. 4C and D). Taken together, these results indi- cated that doxycycline could induce the apoptosis of SCLC cells via inducing the expression of pro-apoptosis proteins (bax and caspase-3) as well as attenuating the expression of anti-apoptosis proteins (bcl-2 and survivin). These results further proved the antitumor activity of doxycycline in SCLC cells.

Tumor invasion and metastasis are the main biological characteristics of malignant tumors, which directly affect the therapeutic effect and prognosis of patients. Compared with NSCLC, SCLC has a more aggressive behavior due to its higher proliferative index and tends to spread in its early stages. Approximately $60-70 \%$ of SCLC patients have a metastatic disease at the time of diagnosis (2). The degradation of the extracellular matrix (ECM) and basement membrane are crucial steps in SCLC cancer invasion and metastasis, and the proteolytic enzymes (MMPs) including MMP-2 and MMP-9 are strongly associated with this process (25). TIMP-2 is the selective inhibitor of MMPs (26). Therefore, we next measured the secretion changes of MMP-2, MMP-9 and TIMP-2 from H446 cells after doxycycline treatment by performing ELISA assay. As shown in Table I, doxycycline decreased the secretion of MMP-2 and MMP-9 into the medium from H446 cells in a dose-dependent manner, whereas it increased the secretion of TIMP-2 at the same time. This finding suggests that doxycycline may reduce SCLC metastasis by inhibiting the degradation of the ECM and basement membrane. Duivenvoorden et al also reported that members of the tetracycline family of antibiotics, including doxycycline, had potential treatment value for bone metastasis as they are also potent MMP inhibitors (11). Golub et al reported that the members of the tetracycline family of antibiotics were potent MMP inhibitors, and were probably able to chelate $\mathrm{Zn}^{2+}$ from the active sites of the MMPs (27). Our findings were consistent with the above studies. In addition, microvascular generation also plays an important role in SCLC cancer invasion and metastasis. Vascular endothelial growth factor (VEGF) is one of the most important angiogenic factors. In the present study, doxycycline also decreased VEGF secretion into the medium from H446 cells in a dose-dependent manner. Collectively, doxycycline suppressed the migration and invasion of $\mathrm{H} 446$ cells via decreasing the secretion of MMP-2, MMP-9 and VEGF, as well as increasing the secretion of TIMP-2.

In conclusion, the present study indicated that doxycycline inhibited the proliferation and colony formation as well as induced apoptosis of SCLC cells. Several apoptotic signal 
pathways, including mitochondrial pathway (bax and bcl-2), caspase activation and the survivin signal pathway seems to be involved in the apoptosis induction effect of doxycycline on SCLC cells. Moreover, doxycycline also suppressed the migration and invasion of $\mathrm{H} 446$ cells by inhibiting the degradation of the ECM and basement membrane as well as angiogenesis. These findings encourage further investigations on the potential of doxycycline as a new therapeutic candidate drug for the treatment of small cell lung cancer.

\section{Acknowledgements}

This study was supported by grants from the National Natural Science Foundation of China (no. 81173014), Guangdong Province Science and Technology Plan Projects (no. 2014A020212197), Guangzhou City Science and Technology Plan Projects (no. 2014J4100144 and the Guangdong Pharmaceutical Association of China (no. 2014D06).

\section{References}

1. Siegel R, Ma J, Zou Z and Jemal A: Cancer statistics, 2014. CA Cancer J Clin 64: 9-29, 2014.

2. van Meerbeeck JP, Fennell DA and De Ruysscher DK: Small-cell lung cancer. Lancet 378: 1741-1755, 2011.

3. Zheng CY, Lam SK, Li YY and Ho JC: Arsenic trioxide-induced cytotoxicity in small cell lung cancer via altered redox homeostasis and mitochondrial integrity. Int J Oncol 46: 1067-1078, 2015.

4. Becker $\mathrm{K}$ and $\mathrm{Xu} \mathrm{Y}$ : Management of tyrosine kinase inhibitor resistance in lung cancer with EGFR mutation. World J Clin Oncol 5: 560-567, 2014.

5. Wan J, Che Y, Kang N and Wu W: SOCS3 blocks HIF-1 $\alpha$ expression to inhibit proliferation and angiogenesis of human small cell lung cancer by downregulating activation of Akt, but not STAT3. Mol Med Rep 12: 83-92, 2015.

6. Hamilton G, Burghuber O and Zeillinger R: Circulating tumor cells in small cell lung cancer: Ex vivo expansion. Lung 193 451-452, 2015.

7. Sun T, Zhao N, Ni CS, Zhao XL, Zhang WZ, Su X, Zhang DF, Gu Q and Sun BC: Doxycycline inhibits the adhesion and migration of melanoma cells by inhibiting the expression and phosphorylation of focal adhesion kinase (FAK). Cancer Lett 285: 141-150, 2009.

8. Liu S, Liu X, Wang H, Zhou Q, Liang Y, Sui A, Yao R, Zhao B and Sun M: Lentiviral vector-mediated doxycycline-inducible USP39 shRNA or cDNA expression in triple-negative breast cancer cells. Oncol Rep 33: 2477-2483, 2015.

9. Chen Z, Wang Y, Liu W, Zhao G, Lee S, Balogh A, Zou Y, Guo Y, Zhang Z, Gu W, et al: Doxycycline inducible Krüppel-like factor 4 lentiviral vector mediates mesenchymal to epithelial transition in ovarian cancer cells. PLoS One 9: e105331, 2014.

10. Son K, Fujioka S, Iida T, Furukawa K, Fujita T, Yamada H, Chiao PJ and Yanaga K: Doxycycline induces apoptosis in PANC-1 pancreatic cancer cells. Anticancer Res 29: 3995-4003, 2009.
11. Duivenvoorden WC, Popović SV, Lhoták S, Seidlitz E, Hirte HW, Tozer RG and Singh G: Doxycycline decreases tumor burden in a bone metastasis model of human breast cancer. Cancer Res 62 : 1588-1591, 2002

12. Shi S, Li X, You B, Shan Y, Cao X and You Y: High Expression of FGFR4 enhances tumor growth and metastasis in nasopharyngeal carcinoma. J Cancer 6: 1245-1254, 2015.

13. Shi Z, Liang YJ, Chen ZS, Wang XW, Wang XH, Ding Y, Chen LM, Yang XP and Fu LW: Reversal of MDR1/Pglycoprotein-mediated multidrug resistance by vector-based RNA interference in vitro and in vivo. Cancer Biol Ther 5: 39-47, 2006.

14. Shen H, Zhao S, Xu Z, Zhu L, Han Y and Ye J: Evodiamine inhibits proliferation and induces apoptosis in gastric cancer cells. Oncol Lett 10: 367-371, 2015.

15. Wang SQ, Liu ST, Zhao BX, Yang FH, Wang YT, Liang QY, Sun YB, Liu Y, Song ZH, Cai Y, et al: Afatinib reverses multidrug resistance in ovarian cancer via dually inhibiting ATP binding cassette subfamily B member 1. Oncotarget 6: 26142-26160, 2015.

16. Gelsomino F, Rossi G and Tiseo M: MET and small-cell lung cancer. Cancers (Basel) 6: 2100-2115, 2014.

17. Attar-Schneider O, Zismanov V, Drucker L and Gottfried M: Secretome of human bone marrow mesenchymal stem cells: an emerging player in lung cancer progression and mechanisms of translation initiation. Tumour Biol: Oct 30, 2015 (Epub ahead of print).

18. Pantziarka P,Sukhatme V,Bouche G, Meheus L and Sukhatme VP: Repurposing Drugs in Oncology (ReDO)-itraconazole as an anticancer agent. E Cancer Med Sci 9: 521, 2015.

19. Sarkar C, Chakroborty D, Dasgupta PS and Basu S: Dopamine is a safe antiangiogenic drug which can also prevent 5-fluorouracil induced neutropenia. Int J Cancer 137: 744-749, 2015.

20. Sellers WR and Fisher DE: Apoptosis and cancer drug targeting. J Clin Invest 104: 1655-1661, 1999.

21. Shea CR, Olack GA, Morrison H, Chen $\mathrm{N}$ and Hasan T: Phototoxicity of lumidoxycycline. J Invest Dermatol 101: 329-333, 1993.

22. Jiang SX, Sato Y, Kuwao S and Kameya T: Expression of bcl-2 oncogene protein is prevalent in small cell lung carcinomas. J Pathol 177: 135-138, 1995.

23. Shi W, Yang J, Li S, Shan X, Liu X, Hua H, Zhao C, Feng Z, Cai Z, Zhang L, et al: Potential involvement of miR-375 in the premalignant progression of oral squamous cell carcinoma mediated via transcription factor KLF5. Oncotarget 6 : 40172-40185, 2015.

24. Christenson JL, Denny EC and Kane SE: t-Darpp overexpression in HER2-positive breast cancer confers a survival advantage in lapatinib. Oncotarget 6: 33134-33145, 2015.

25. Qin Y, Zhang Q, Lee S, Zhong WL, Liu YR, Liu HJ, Zhao D, Chen S, Xiao T, Meng J, et al: Doxycycline reverses epithelialto-mesenchymal transition and suppresses the proliferation and metastasis of lung cancer cells. Oncotarget 6: 40667-40679, 2015.

26. Ricci S, Bruzzese D and DI Carlo A: Evaluation of MMP-2, MMP-9, TIMP-1, TIMP-2, NGAL and MMP-9/NGAL complex in urine and sera from patients with bladder cancer. Oncol Lett 10: 2527-2532, 2015

27. Golub LM, Ramamurthy NS, McNamara TF, Greenwald RA and Rifkin BR: Tetracyclines inhibit connective tissue breakdown: new therapeutic implications for an old family of drugs. Crit Rev Oral Biol Med 2: 297-321, 1991. 